\title{
Probe on Production-Education-Research-Model of Measurement and Control Technology Professional based on the Automatic Dismantling Line Platform
}

\author{
Wang Sujuan \\ Shanghai Second Polytechnic University \\ Shanghai, China \\ sjwang@sspu.edu.cn
}

\author{
Qin Qin, ChenBaoyu, LiuZhenguo \\ Shanghai Second Polytechnic University \\ Shanghai, China \\ qinqin@sspu.edu.cn
}

\begin{abstract}
This article summarizes and discusses the combination of Producing-Learning-Researching Cooperation of measurement and control technology professional based on the platform of the research and development of automatic dismantling line. In the process of project research and development, many teachers and students and cooperative enterprises participate it, which promote the teachers' scientific research ability, improve the students' practical ability and employment ability and deepen the depth of cooperation between colleges.
\end{abstract}

Keywords-Producing-Learning-Researching model; practice; Measurement and control technology professional

Measurement and Control Technology Professional is the multi-knowledge crossed which involves electronic, optical, mechanical, computer technology, automatic control, information technology and so on. It is a new and high technology intensive multidisciplinary and involves a wide range of disciplines and technologies [2], which makes the requirements of training professional talents is high and difficult. Measurement and control professional in our school actively carries out the developing mode of ProducingLearning-Researching Cooperation in the platform of automatic disassembly line, which improves the teachers' scientific research and teaching ability, improves the students' practical ability and employment competitiveness and deepens the school enterprise cooperation.

\section{INTRODUCTION OF AUTOMATED DISASSEMBLY LINE}

The main task of the project of Automatic dismantling line is to design a line to disassemble waste liquid crystal display automatically to several independent parts including LCD screen, circuit boards, plastic shell and the metal cover to recycle respectively. This project is a key technique in the field of electronic wastes resource utilization, and has a vital significance and market prospects.

Key technologies of this project include the identification of LCD screen, the mechanical design of the production line, the motion control of the work piece, the application of laser cutting, robot control and machine vision, which relate to many technologies such as mechanical, electronic, sensor, motion control, machine vision, equipment communication and so on.

Currently the first generation of this project has been completed design, assembly, installation and commissioning, and entered the assembly line overall integrated debugging stage. The first generation of products is designed for DELL and HP 17 inch display. Basing on the successful operation of the first generation of products, we will expand the scope of the image, increase the brand and model, so as to form the two generation, three generation and other follow-up products.

\section{EFFECT OF INDUSTRY-UNIVERSITY-RESEARCH COOPERATION}

In the research and development process of the automatic disassembly line, through the active participation of teachers and students, through the good communication with the cooperative enterprises, not only the project has been successfully pushed forward, but also the teachers, students and enterprises have benefited a lot from it.

\section{A. Improve teachers' teaching and scientific research ability}

Teachers participating in the project, performing their duties, are responsible for the overall planning, mechanical design, and purchase of laser, robot control, PLC software design and machine vision program design respectively. With the progress of the project, teachers in responsible area through continuous learning, exploration, practice, successfully completing of various tasks, not only improve the

This article is sponsored by the cultivate discipline: detection technology and automation devices in Shanghai second polytechnic university. Sponsor number: XXKPY1304 
level of scientific research, but improve the content of their own teaching. As with the industry into the 4.0 times, industrial robots in industrial pipeline is applied more and more widely, Our Measurement and Control Technology Professional, following the pace of technological development, timely adjust the practice of student projects by increasing the content of industrial robot . Initially we only have a general idea, but have no clear ideas on how to design the specific content of the practice. Through the practice of this project, we quickly design a plurality of practice projects including knowing the robot's coordinate system, robot teaching, robot programming, robot simulation, robot extract storage. In addition, the current curriculum of Measurement and Control Technology Professional has the following problems: knowledge dispersed and lacking the integrated using of knowledge points, which results in students' lacking comprehensive application ability to apply knowledge of this major during the period of school exercise. From the project practice, we get inspired and design a comprehensive experimental device and set up corresponding courses. The curriculum contents include using PLC to control the sliding platform to carry the work piece, machine vision device to detect defects in the work piece, and the robot to crawl into the waste repository, so that students can integrate use of the professional knowledge through this experimental device to complete a entire system's designing and debugging, to exercise their comprehensive ability.

\section{B. Improve students' practical ability and Employment Competitiveness}

In the research and development process of automatic dismantling line, many students participate in it and their practical ability is promoted quickly. Some of knowledge used in this project has been learned early by these students, such as PLC application. Through the practice of this project, these students not only deepen understanding of this knowledge, but also exercise their ability about solving problems. In the actual project development process, there will be many unexpected problems. For example, in the motion control of two work pieces, the programs are completely same, but the one is normal, the always has a deviation. Finally, the students found that the motion controller is not initialized leading to its action error, and ultimately solved this problem. Through the mistake the students further understand the importance of initialization.

The project also involves much knowledge that students did not learn before, such as industrial robot teaching and programming, industrial camera application. By learning from teachers, communicating with manufacturers and seeing the manual work means, eventually our students are able to operate such equipment in a short period of time. Through the exercise, the students' abilities of self-study, communication with manufacturers and engineering quality are improved. So, cooperative enterprises have high salary invites to our students after to see their comprehensive strength.

\section{Deepen cooperation with enterprises}

In the research and development process of automatic dismantling line, the project team successively carries out exchanges and cooperation with assembly manufacturers, suppliers of industrial robots, machine vision suppliers and other enterprises. We not only convey to these partnerships with high-quality graduate students, but through the cooperation in this project, the project team and enterprise implement complementary advantages to achieve a win-win effect. As is known to all, the advantages of universities are having a large number of senior specialized talents, having a deep knowledge of frontier science and technology development and having conditions to timely grasp the commanding heights of science and technology of new information in the world. While, the advantages of enterprises are their mastering the market information, having financial strength and manufacturing advantages. [3] Companies put forward pertinent Suggestions for automatic disassembly line and production to meet the requirements of our products. We provide enterprises with innovative ideas. As in the dismantling of LCD monitor internal metal mask, we, through the experiment to compare the effect of various cutting tools, finally confirmed with laser cutting. Laser manufacturers according to the requirements that we provided on the technical parameters and appearance of the size, in the end produced the laser that meets these requirements, which make their products richer in turn.

\section{EXPERIENCE ON THE COOPERATION OF INDUSTRY UNIVERSITY RESEARCH}

Throughout the whole development of automatic dismantling line, from setting up the project to project demonstration, the overall planning, division of the installation and commissioning, the teachers, students and businesses participating in it have been a great harvest. We get the following three points about the Producing-LearningResearching model.

(1) Producing, learning and researching are intertwining in the modern campus, which weave out a communication net inside and outside the campus information network [4]. This information network improves the teachers' ability of teaching and scientific research by providing the basis for the adjustment of curriculum and teaching contents, which is an important condition for modern higher personnel training. It is impossible to achieve the comprehensive development of the quality of the people without this information network.

(2) Engineering ability is an important ability for measure and control engineering college students. It is also the foundation for cultivating students' innovation ability [5]. 
Producing-Learning-Researching cooperation can let the students get into practice engineering, therefore, to make students participate in the research to improve their comprehensive quality.

(3) For the long-term sustainable development of Producing-Learning-Researching cooperation, we must adapt to the development of the industry, and effectively solve the key technical problems.

\section{REFERENCES}

[1] Zhou Xiaoyong. The construction and implementation of application oriented talent cultivation system for measurement and control technology and instrument [J], high education forum, 2009,5:52-58

[2] Tang Xiaoyun, Liu Jingcheng. Research and practice of innovative personnel training of undergraduate of measurement and control technology and instrument [J], Chinese university teaching, 2009,6:3032

[3] Li Zhenxiong. Research and development of independent brands of high-end products and technology, product and technology, 2007,3 (6):89-94

[4] Fan is Rev. On the research mode of higher education [J]. Journal of Inner Mongolia Normal University, 2002,2 (15):15-20

[5] Ding Taiyuan, Fang Ping, Ma Xiao an. Exploration and practice of strengthening engineering practice ability cultivation of engineering students $[\mathrm{J}]$. Heilongjiang Education: research and evaluation of higher education, 2009 (5):60 